\title{
The Role of Communicating Uncertainty and Information Subsidies on News Media Representation of the Female Condom's Efficacy
}

\author{
Karishma Chatterjee ${ }^{1}$ \\ ${ }^{1}$ Department of Communication, The University of Texas at Arlington, Texas \\ Correspondence: Karishma Chatterjee, Department of Communication, Box 19107, FAB 118, The University of Texas \\ at Arlington, Arlington, TX 76019. E-mail: chatterjee@uta.edu
}

Received: April 14, 2014 Accepted: May 3, 2014 Available online: May 19, 2014

doi:10.11114/smc.v2i1.389

URL: http://dx.doi.org/10.11114/smc.v2i1.389

\begin{abstract}
We used the framework of communicating uncertainty and information subsidies to examine the efficacy claims about the female condom Reality, regarding unplanned pregnancy and HIV/STI prevention that were made in the manufacturer's news releases, U.S. Food and Drug Administration pre-market approval news release and in wire service stories and newspaper stories from 1992 - 1993. The efficacy claims were juxtaposed with the empirical evidence regarding the efficacy of the female condom, as well as with the U.S. Food and Drug Administration (FDA) regulations. Qualitative content analysis suggested that the FDA's efficacy claims as compared to the manufacturer's claims dominated newspaper and wire service stories during the time female condom received pre-market approval. A majority of the news articles did not present a balanced or an accurate picture of the female condom's efficacy. The findings suggest the contested nature of the efficacy claims as evidenced by how they were represented in the news media. The study also highlights the challenges of communicating uncertainty about a medical device when scientists themselves seem to disagree on the manageability of the uncertainty.
\end{abstract}

Keywords: female condom, communicating uncertainty, information subsidies

\section{Introduction}

People rely on news sources for health information, especially to translate jargon-infused complex information to more readily understood information (Parrott \& Condit, 1996). This includes information about new medical technologies and devices. Reality ${ }^{\circledR}$ was the first female condom to be approved by the United States Food and Drug Administration (FDA) in 1993 (Leary, 1993). Conceived of as the first woman-initiated barrier method providing protection against both sexually transmitted infections (STIs) and unplanned pregnancy, U.S. sales of Reality® only made up $10 \%$ of its 34.7 million unit sales in 2008 (Heavey, 2009). Many factors have been identified with its lack of commercial success in the U.S (Kaler, 2004a, 2004b) including the role of the media (Chatterjee \& Markham Shaw, 2012; Kaler, 2004a). Kaler (2004a) argued that media accounts constructed the female condom to be a joke, and Chatterjee and Markham Shaw (2012) found that overall news media presented mixed portrayals of the female condom, with international news stories providing more positive depictions than the domestic stories. In addition, Chatterjee and Markham Shaw (2012) reported that the FDA commissioner David Kessler, when announcing the approval of the female condom, was quoted as saying that the male latex condom remained the best choice against AIDS and STIs protection. They suggested, “...when credible sources frame a new technology in a negative light, early adopters may form corresponding negative impressions" (p. 11).

The United States Food and Drug Administration is the apex regulatory body for medical devices. The success of a medical device involves meeting the FDA approval process, conducting efficient clinical trials, and evaluating the marketplace (Keagy \& Levin, 2012, p. 36). Manufacturers have to follow FDA guidelines to meet submission approval prior to manufacturing a device. Given that a medical device needs FDA approval before it can be available in the marketplace, Kessler's statement seems anomalous. Chatterjee and Markham-Shaw (2012) suggested that Kessler's comment - cited in the top national newspapers - may have served to introduce the female condom as an "inferior medical device" (p.11). Why would the head of a federal agency responsible for the regulation and approval of medical devices suggest uncertainty about the efficacy of a device that it had approved? The goal of this study is to examine various efficacy claims made regarding the female condom by the FDA, the manufacturer, and the empirical evidence and to examine how the various claims were reported in the news media. 


\subsection{Female Condom}

The first generation Reality female condom FC1 was developed as the first female-initiated barrier method available in the United States. Marketed as Femidom in Europe, it was launched in Switzerland in February 1992 and in the United Kingdom in September 1992. In January 1992, an FDA advisory panel unanimously recommended that the FDA approve the Reality female condom premarket approval application subject to the completion of a pregnancy effectiveness study along with the provision of additional data, which Wisconsin Pharmacal Company, Inc. (WPCI) submitted on July 31, 1992 (PR Newswire, August 3, 1992). The obstetrics and Gynecology Devices Panel of FDA recommended that Reality be approved in December 1992. WPCI had the exclusive rights to market Reality in the United States, Canada and Mexico. Chartex International Plc, a British health care company, owned the worldwide rights to the product (Business Wire, December 10, 1992).

Reality was conceived to differ from the male condom as a barrier method in four ways. First, women could initiate protection from STIs and unplanned pregnancy whereas the male condom remained a male prerogative. Second, when inserted correctly, the female condom offered more coverage to both partners. Third, made out of polyurethane, a soft and thin sheath, the device had two flexible rings - one placed inside whereas the second ring covered the outer genitalia - the material was stronger than latex and provided people who have latex allergies with protection against semen and STIs. Fourth, it would be less disruptive to sexual intercourse as women could wear it long before sex was initiated, and unlike male condoms, the male partner did not need to have an erection in order to use the condom (Leeper \& Conrardy, 1989).

The Female Health Company (FHC), formally known as Wisconsin Pharmacal, manufactures, markets, and sells the second generation product FC2® introduced in 2009 in the U.S. (FemaleHealthCompany.com). The FC2® is distributed through public health organizations and is available in select retail stores. The FDA recommends in its summary of labeling that in rare cases users may experience discomfort during insertion, pain after insertion, before sex, discomfort during sex, and burning sensation, rash or itching (http://www.accessdata.fda.gov/cdrh_docs/pdf8/P080002c.pdf). As with any barrier method, education and learning how to use it correctly is important for successful and consistent use (Artz et al., 2000).

\section{Theoretical Framework}

The literatures on information subsidies as well as the literature on the communication of uncertainty in science communication form the theoretical backbone of this study.

\subsection{Information Subsidies}

Journalists often rely upon press releases as the basis for news articles (McCarthy, Brennan, De Boer, \& Ritson, 2008; Nelkin, 1995); often, press releases serve as a means for research institutions to "influence how the research is translated into news" (Woloshin \& Schwartz, 2002, p.2858). Gandy (1982) suggested that organizations often provide information subsidies in the form of news releases, press kits, news conferences, and other public relations activities to the media in an effort to provide them easy access to information. An information subsidy is "an attempt to produce influence over the actions of others by controlling their access to and use of information relevant to those actions" (Gandy, 1982, p. 61). This information is considered a subsidy because as Gandy argues, the source of the subsidy makes it available at a price "less than the cost a user would face in the absence of the subsidy" (p. 61). The information is considered valuable because "of its expected utility in reducing uncertainty about some future action of decision" (p. 61).

Information subsidies can be used by organizations strategically to promote an issue or candidate (Kiousis, Kim, McDevitt, \& Ostrowski, 2009) or repair their image in the face of crisis (Caldiero, Taylor \& Ungureanu, 2009). Caldiero et al. found that newspapers in their coverage of organization fraud crisis used company background information and quotations from company officials that had been included in the news releases. They suggest that organizations have an opportunity to provide their side of the story or even potentially frame a story. Kiousis et al. (2009) similarly found that news releases were somewhat effective in building issue and attribute agendas in newspaper content.

Given the impact of news releases on news content we examined Reality's manufacturer, Wisconsin Pharmacal's news releases and the FDA news release regarding the device's pre-market approval.

\subsection{Communicating Uncertainty in Science Communication}

Scientific uncertainty is commonly defined as the "uncertainty brought about by either a lack of scientific knowledge or disagreement over the knowledge that currently exists" (Freidman, Dunwoody, \& Rogers, 1999, p. xiii). Previous research on the female condom suggests that there were disagreements over the efficacy claims or the knowledge claims (e.g., Chatterjee \& Markham Shaw, 2012). This study seeks to extend the literature by examining the reasons behind the disagreements. 
The challenge of dealing, representing, and responding to uncertainty in science via science communication is well documented (see Friedman, Dunwoody, \& Rogers, 1999 for a review). Dunwoody (1999) suggested that journalists commonly use either objectivity or balance to deal with conflicting truth claims. Objectivity entails an accurate representation of the message along with attribution of sources whereas balance includes presenting a range of viewpoints. Thus, we also measured how the truth claims were represented and the range of sources that were attributed to the efficacy claims about the female condom.

\subsection{Research Questions}

Given the role of the FDA in the approval and regulation process of medical devices, we posed the first research question to provide a context to the claims:

$\mathrm{RQ1}$ : What were the FDA requirements in regards to the market approval of the female condom?

Once the FDA has granted market approval for a medical device, the primary sources of new medical technology assessment information used by health care providers and payers are peer-reviewed journals and information from manufacturers (Luce and Brown, 1994). Hence, we also examined the empirical research on the effectiveness of the female condom as offering both protection against STIs and unplanned pregnancies.

RQ2: What STI and pregnancy efficacy claims regarding the female condom were available in peer-reviewed medical journals?

The next set of research questions examined the communication of the uncertainty regarding the efficacy of the female condom.

RQ3a: How were efficacy claims represented in newspapers and wire service stories?

RQ3b: What sources were used in support of the efficacy claims in newspapers and wire service stories?

The last set of research questions connects the literature on information subsidies with news media coverage.

RQ4a: What is the relationship of the efficacy claims mentioned in the FDA news release to newspaper and wire service coverage of the female condom?

RQ4b: What is the relationship of the efficacy claims included in the manufacture's news releases to newspaper and wire service coverage of the female condom?

\section{Method}

We triangulated the data to examine the seemingly contradictory statement issued by Kessler in the FDA news release regarding the efficacy of the female condom. We analyzed four data sets: the FDA-issued news release, Wisconsin Pharmacal's news releases (1992-1993); newspaper stories from the top five daily newspapers in the United States during 1992 and 1993 according to the Editor \& Publisher International Yearbook; news wire stories (1992-1993); Publication 91-4424, the FDA guidelines for medical devices; and, empirical evidence in peer-reviewed medical journals regarding the female condom's efficacy (1988-1993). The FDA issued news release was obtained from FDA's website, and the other data were retrieved through library resources. Next, we briefly summarize how we gathered the data samples through the databases.

\subsection{Data Sources and Sampling Procedures}

The LexisNexis Database was used for procuring the news release, wire service stories, and newspaper stories of USA Today, The New York Times, and The Washington Post from the years 1992 and 1993. The Factiva database was used for accessing The Wall Street Journal stories. The Proquest database enabled us to get Los Angeles Times news stories only for 1993. The use of the search term "female condom" yielded 126 articles. Articles were excluded if the female condom was mentioned in passing, if the news release contained only WPSI quarterly financial results, or the story was a duplicate. The final sample consisted of 71 articles: 17 news releases, 30 wire service stories, and 24 newspaper stories. [1]

A survey of peer-reviewed articles was conducted in EBSCO host that included: Health Source: Nursing/ Academic Edition that houses 550 full text journals; and MEDLINE, created by the National Library of Science, that accesses from more than 4,800 biomedical journals. Two searches were conducted for the time block $1988-1995$ with the terms "female condom" and "effectiveness" and "female condom" and "efficacy" in the titles. This is because research on the female condom was already underway by the late 1980s (Wisconsin Pharmacal, May 10, 1993). We also located a study that Wisconsin Pharmacal referenced in its news releases. Thus, we had a total of three published peer-reviewed articles.

\subsection{Sample}

The final sample consisted of 17 Wisconsin Pharmacal issued news releases, 30 wire service stories, and 24 newspaper 
stories. The wire service stories comprised of the Associated Press (14), United Press International (6), PR Newswire (3), Abortion Report (2), Xinhua General News Service (2), Agence France-Presse (1), and American Health Line (1). The newspapers consisted of The Washington Post (7), USA Today (7), The New York Times (4), The Wall Street Journal (4), and Los Angeles Times (2).

\subsection{Coding Procedures}

Three coders read a majority of the articles (66\%). We employed qualitative content analysis to code the newspaper and wire service stories for efficacy claims. Specifically, the coders noted the following: whether efficacy claims were included in the story or not $(\mathrm{Y} / \mathrm{N})$; whether efficacy claims were made in regards to STI/HIV prevention, unplanned pregnancy prevention or both; whether percentages or some numerical data was provided or not; specific labels or phrases used to represent the numerical data; whether the source of the claims (e.g., a study, a researcher, etc.) were provided or not; and the number of sources used in the article. The coders followed an iterative process of grouping and categorizing the data. Once the data started to yield patterns in how the claims were represented, the author coded the rest of the data. Disagreements were sorted through discussions. In qualitative inquiry, validation of interpretation may be achieved by triangulation and disjuncture (Lindlof \& Taylor, 2002). Triangulation involves comparing two or more sources of evidence of using multiple methods. Disjuncture refers to the differences in perspectives produced by different data sources and methods. The different data sources used in this study serve to "account for a more complex social reality than was first imagined" (Lindlof \& Taylor, p. 242) regarding the communication of the uncertainty regarding the efficacy of the female condom in newspaper and wire service stories.

Publication 91-4244 was first analyzed, followed by the published empirical evidence regarding female condom's efficacy, the FDA news release, and finally the manufacturer's news releases, newspaper stories and wire service stories.

\section{Results}

\subsection{Publication 91-4244}

Any medical device intended to offer protection from AIDS needs to meet certain FDA guidelines as mandated in Publication FDA 91-4244, that details all the steps that a device manufacturer needs to take, from pre-clinical trials to the packaging of the device, to meet submission approval prior to manufacturing the device (RQ1). For example, the booklet specifies that the packaging for male condoms needs instructions for use, as well as information such as an AIDS prevention message and the intended use(s), and whether the device is for disease and/or pregnancy prevention.

The guidelines for female barrier contraceptive devices were prepared in 1989 through the collaborative effort of experts from the FDA, the National Institute of Child Health and Human Development (NICHD), and the Centers for Disease Control (CDC) along with "substantial interactive dialogue with the public" (Rivera, 1991, p. 45). These guidelines were developed to expedite device study and evaluation, given the rising concerns for HIV and AIDS and thus, the need for AIDS-related devices in the marketplace.

This document noted "Because of the extreme difficulty in studying effects on STD rates in a clinical trial, the guidelines designate pregnancy as a surrogate study endpoint for demonstrating the device's effectiveness in preventing transmission of STDs" (Rivera, 1991, p. 45). It also mentioned eliminating the requirement for a randomized controlled clinical trial to compare the performance of the new device to that of an established barrier contraceptive device in a concurrent control group (p. 45). However, the document mentioned the need for a feasibility study (phase I) including health risks and device displacement during use as well as the need for a nonrandomized clinical trial in Phase II. Overall, the design and material of the medical device needed to be examined before clinical studies and the results of the clinical studies needed to support the efficacy of the device, leading to a "risk-benefit" assessment.

The document listed the various steps that needed to be taken during preclinical studies (prior to phase 1), which included comparing it to an established device such as the latex male condom. One of the necessary conditions was to "Demonstrate that the barrier performance of the new device is as good or better than that of the reference device" ( $p$. 47). Because Phase III (randomized controlled clinical trial) was eliminated, emphasis would be placed on phase II. Evaluation of the new device would need to include comparisons with an appropriate control group such as a diaphragm or cervical cap and a comparable population profile comprising at the minimum 200 participants. Of final note is that although the duration of such studies is 12 months, the CDRH could permit "submission of a PMA [pre-manufacturing approval] application with a 6-month (or less) life table analysis" (Rivera, p. 51).

\subsection{Empirical Evidence Regarding the Effectiveness of the Female Condom}

Three peer-reviewed articles were analyzed to answer the second research question. Dorflinger, Farr, Gabelnick, and Sturgen (1994) examined the contraceptive efficacy of the female condom specifically to provide data about the device to the FDA. Following FDA guidelines, the clinical trial, consisting of a total of 328 female participants were drawn from six US sites and three sites in Latin America. Twenty-two US participants and 17 Latin American participants 
became pregnant, yielding 6-month accidental pregnancy rates of $12.4 \%$ and $22.2 \%$, respectively. During consistent and correct use of the device, the pregnancy rates were $2.6 \%$ and $9.5 \%$ for the US and Latin American participants. No serious "adverse" effects were reported. The scholars concluded that the contraceptive efficacy of the female condom was in the same range as other barrier methods when used consistently and correctly although no "absolute statement" could me made because the clinical trials were non-comparative (p. 1964).

Similarly, that same year, Trussell, Sturgen, Strickler, and Dominik (1994) in their analysis of comparing the contraceptive efficacy of the female condom with other methods concluded that in the absence of randomized clinical trials with another method of contraception "no definite conclusion regarding its comparative efficacy is possible" (p. 71). Through inferential statistics, they found that the contraceptive efficacy of the female condom during typical use was statistically indistinguishable from that of the diaphragm, the sponge or the cervical cap among women in the United States.

The authors noted that should all four methods offer the same contraceptive efficacy, the failure rates for the female condom would be higher than the others because, unlike the other trials, the female condom trial excluded women with low coital frequency, counted chemically confirmed pregnancies even when they were not clinically confirmed, and lost a much smaller percentage of the sample to follow-up. The authors argued that statistical comparisons of the contraceptive efficacies of the female condom and the male condom were not possible; they believed that the contraceptive efficacy of the female condom was probably closer to that of the male condom. On the basis of the device's contraceptive efficacy, the female condom appeared to have great potential for reducing a woman's risk of acquiring HIV.

The authors explained that published studies of contraceptive efficacy of methods designed for long-term use such as IUDSs and implants typically report probabilities of failure at 12 months and longer. However, high rates of discontinuation among users of female barrier methods and the need for a timely review and approval of a female-controlled STD prophylactic deemed it appropriate to evaluate the female condom in controlled trials of less than 12 months duration.

Finally, Soper et al. (1993) in an experiment with 104 women found that the compliant (use of the female condom each time they had sexual intercourse) use of the female condom was effective in preventing recurrent vaginal trichomoniasis, an STI, in all twenty of the participants as compared to the control group and the non-compliant group.

\subsection{The FDA Issued News Release}

The FDA's statement sent via a news release on April 27, 1993 in the first paragraph mentioned that the FDA was prepared to approve the female condom provided the manufacturer included in the female condom's labeling that for highly effective protection against STDs including AIDS, it is important to use latex condoms for men. In addition, the approval was conditional on the labeling comparing the pregnancy rate of 26 percent per year to rates for other women's barrier contraceptives, which are lower and that the manufacturer must take part in additional effectiveness studies for the product.

The news release noted the FDA had reservations about the limited data available on protection the female condom offered against STDs, as well as about the high pregnancy rate among users, the small number of women in the clinical studies and the short duration of the studies, which lasted less than a year. Towards the end of the news release, some of the study details were provided such as the study consisted of 200 women who used the device for six months. The six-month pregnancy rate among U.S. women in the sample who used the female condom was approximately 12.5 percent - or an estimated 26 percent per year. The high rate was believed to have been the result of improper use of the device. It compared to an expected rate of 85 percent among women not using any contraceptive method. The FDA concluded that women who use the device correctly each and every time they have intercourse could expect a much lower pregnancy rate.

\subsection{Wisconsin Pharmacal News Releases}

Forty-seven percent of WP's news releases were in 1992 and the remaining 53\% were from 1993.

\subsubsection{Presence of efficacy claims}

All the news releases contained HIV/STI as well as pregnancy prevention claims.

\subsubsection{Presentation of efficacy claims}

Efficacy claims were denoted in the articles in the form of statistical information with $35 \%$ of news releases containing statistical information; six of these stories either used the label "success rate" or "success reported". From the time Wisconsin Pharmacal submitted the pregnancy effectiveness data to the FDA (Wisconsin Pharmacal, August 31, 1992) until December of that year, the company issued periodic news releases. Three of them mentioned that Reality had been clinically tested in 71 medical centers involving 1,700 couples and 30,000 uses demonstrating that it prevents 
pregnancy and reduces disease. The female condom had already been launched in the UK as Femidom and launched in Switzerland in February 1992. In 1993, four of the news releases from January until April 7 noted the $88 \%$ success rate, along with $95 \%$ projected success rate with perfect use and a reduction in HIV rates by $93 \%$ if FC was used correctly in every act of intercourse.

On the day the FDA issued its statement regarding the approval of the female condom WP issued a news release that mentioned that "While REALITY has not been tested as extensively as other barrier contraceptives, the studies, involving over 1,700 women and 30,000 uses of the device, demonstrate that REALITY prevents pregnancy and reduces the risk of STDs, including AIDS" (PR Newswire, April 27, 2003). Finally, a news release dated May10, 1993, noted that the 6-month pregnancy rate was $13 \%$ and that the estimated pregnancy rate for a year had a range between $21-26 \%$.

Efficacy claims were included without statistical information in $23.5 \%$ of the news releases. A news release in early July reported on the clinical study by Soper and colleagues that showed that Reality was effective in preventing an sexually transmitted infection vaginal trichomoniasis when used properly every time (PR Newswire, July 6, 1993). The remaining two news releases in that month reported the FDA approval. For example, "REALITY is the first and only female condom approved by FDA, the only product under a woman's control that helps to prevent unintended pregnancy and sexually transmitted disease, including AIDS..." (PR Newswire, July 9, 1993). Both the news releases also included the FDA suggested labeling information without the pregnancy rates. The last available news release in 1993 mentioned Leeper's presentation about the role of small business in innovative health care products to the U.S. House of Representatives: "In her remarks, Dr. Leeper stressed the importance of research on new methods which are designed to prevent disease, such as the Reality female condom. Reality, which is sold to the public sector at a reduced price, helps prevent AIDS, other sexually transmitted diseases and pregnancy."

\subsection{Newspaper Stories}

\subsubsection{Presence of efficacy claims}

Nearly ninety-six percent of the newspaper stories contained efficacy claims about the female condom. In addition, $75 \%$ of the stories in 1993 had efficacy claims as compared to $68 \%$ of the stories in 1992 . More claims were made about the STI/HIV and pregnancy prevention collectively than about STI/HIV prevention and pregnancy prevention individually.

\subsubsection{Presentation of efficacy claims}

The majority (58\%) of the newspaper stories used either "pregnancy rate" or "failure" rate to describe the numerical data; $36 \%$ stories used "pregnancy rate" whereas $21.7 \%$ stories used "failure rate".

In 1992, the newspaper stories used percentages ranging from " $5 \%$ over 6 months, and 12\% if not used every time" to $15.1 \%$ over 6 months. In 1993, the stories that provided numerical information included " $26 \%$ ". There were variations in how the numerical information was presented such as " $26 \%$ for 6 months", " $26 \%$ a year", " 21 to $26 \%$ with $10 \%$ during correct use", and simply " $26 \%$."

For example, in a 1992 article the staff writer stated: "Allowing for imperfect use- putting it in wrong or only part of the time, for example, - gives the female condom a 12.2 percent failure rate, somewhat higher than other barrier methods for preventing pregnancy" (The Washington Post, December 22, 1992). In another article published the day after the FDA approval in 1993, the staff writer wrote "The labels also must compare the pregnancy rate for female condom users, about $26 \%$ a year in U.S. trials, with rates for other female barrier contraceptives, which are lower" (The Wall Street Journal, April 28, 1993).

\subsection{Wire Service Stories}

\subsubsection{Presence of efficacy claims}

Ninety-six percent of the wire service stories had efficacy claims. A majority $(86.6 \%)$ of the wire service stories about the female condom were in 1993.

\subsubsection{Presentation of efficacy claims}

In regards to the labels used, $41.3 \%$ of wire service stories used "failure rate," $13.7 \%$ stories used "pregnancy rate," and $10.3 \%$ stories employed either the word "success reported" or "success rate" to qualify the efficacy of the female condom.

All four of the wire stories from 1992 were found in December around the time the FDA panel convened to assess the effectiveness study. All four wire service stories reported that the female condom had a failure rate of $12.2 \%$ over 6 months; three of these stories included that the FDA considered that this rate was under-reported by $10 \%$ because the use of the device in Latin America showed a failure rate as high as 30 percent. Two wire stories noted that the female 
condom had an $88 \%$ success rate over 6 months and $95 \%$ success rate if used properly every time.

In early January of 1993, a news wire service reported that the female condom had an $88 \%$ success rate reported over 6 months. The FDA sent out a news release on April 26, 1993, about preparing to approve the FC with restrictive labeling. Eleven wire service stories were found from April 27 until the end of May. There was variation in how the efficacy claims were represented. Three out of five wire stories mentioned that the $26 \%$ failure rate occurred over a 6 -month long study, whereas two stories simply indicated that the failure rate was $26 \%$. Two stories noted that the pregnancy rate was $26 \%$ a year based on a six-month study of 200 women. Two stories mentioned that $26 \%$ of women got pregnant over six months. One story reported that the female condom had a $12.5 \%$ failure rate in six months. Finally, a wire service story in August 5 reported a 28\% failure rate for a 6-month period and a wire story on December 10 , 1993 reported a $26 \%$ failure rate.

Taken together, the newspaper and wire service stories seemed to have provided a partially objective or accurate representation of the efficacy claims (Q3a).

\subsection{Sources of Efficacy Claims}

We examined the sources of the efficacy claims to ascertain whether there was balance in the reporting of efficacy claims by the newspapers and news wire stories (RQ3b). We also examined the sources in the manufacturer's news releases. In 1992, In September and October Wisconsin Pharmacal's news releases cited that the female condom had been tested at 71 medical centers and 10 countries as well as mentioned the major study, the pregnancy use effectiveness study sponsored by the United States Agency for International Development (USAID) and implemented by Family Health International and the Contraceptive Research and Development Program (CONRAD). The six-month clinical study was mentioned in $47 \%$ of the news releases, followed by the Trussell et al. study $(23.5 \%)$.

The wire service stories cited the six-month clinical study (44.8\%), a Wisconsin Pharmacal spokesperson (27.5\%), the FDA $(24.1 \%)$, no sources $(17.2 \%)$, the World Health Organization (6.8\%), Public health experts $(6.8 \%)$, the Centers for Disease Control and Prevention (3.4\%), the Allan Guttmacher Institute (3.4\%), and the Trussell Study (3.4\%) when making efficacy claims.

Newspapers cited a Wisconsin Pharmacal spokesperson (39.1\%), the FDA (39.1\%), the six-month clinical study (30.4\%), no sources (4.3\%), the World Health Organization (4.3\%), the Centers for Disease Control and Prevention (4.3\%), AIDS research foundation (4.3\%), and the Trussell et al. Study (4.3\%) and the Soper et al. Study (4.3\%) when making efficacy claims.

Both, newspapers and wire service stories had slightly more stories with single sources as compared to multiple sources. Just over $52 \%$ of newspaper stories had single sources and $43.4 \%$ of newspaper stories had multiple sources. Similarly, just over $51 \%$ of wire service stories had single sources whereas $31.3 \%$ of wire service stories had multiple sources. Thus, cumulatively, less than half of the newspaper and wire service stories tried to present a balanced view on the efficacy of the female condom (Q3b).

\subsection{Relationship between Efficacy Claims in the FDA News Release and Manufacturer's News Releases to Newspaper and Wire Service Stories}

In order to assess the relationship between the FDA news release, WP's news releases and the representation of the efficacy claims in the newspapers and wire service stories (RQ4a; RQ4b) it is important to bear in mind that there seemed to be four news cycles: January 1992 when the FDA advisory panel first recommended that the FDA approve the female condom subject to the completion of the pregnancy effectiveness data; July 1992 when Wisconsin Pharmacal submitted the data; December 1992 when the FDA panel gave conditional approval with label change; and April 1993 when the FDA issued its statement regarding Reality's pre-market approval. This contextual information is useful in understanding the interplay between the news releases and the newspaper and wire stories.

We see the influence of both WP as well as the FDA in the first three news cycles. For example, in December 1992 information from the news releases issued by WP around the time the FDA reviewed the premarket approval was cited by all four wire service stories at that time. These stories also included that some FDA officials were concerned about the efficacy of the female condom.

In the fourth cycle, the claims reported by the FDA were predominant. These were inferred from the phrases and labels that were used as well as the numerical representation of the female condom's efficacy. The FDA news release called it "the pregnancy rate" (Statement by the FDA, April 26, 1993), and the news releases issued by Wisconsin Pharmacal couched it as the "success rate." A larger proportion of wire service stories $(41.3 \%)$ than newspaper stories $(21.7 \%)$ qualified the efficacy of the female condom as a "failure rate". A larger proportion of newspaper stories used the "pregnancy rate" as compared to wire service stories, and none of the newspaper stories used the term "success rate." It is worth noting that the wire stories started using the term "failure rate" after the FDA news release. 
Lastly, the predominance of the FDA claims can also be inferred when Wisconsin Pharmacal issued a news release on May10, 1993, noting that the 6-month pregnancy rate was $13 \%$ and that the estimated pregnancy rate for a year had a range between 21-26\%. Only one wire story (UPI, May 10,1993) among the other eight wire stories that month as well as a newspaper story (The New York Times, May 11, 1993,) among the other two newspaper stories reported the pregnancy rate was $13 \%$ in 6 months. To summarize, efficacy claims made both by the manufacturer and the FDA were included in the first three news cycles, however, the FDA claims seemed to have dominated the fourth news cycle (RQ4a \& RQ4b).

\section{Discussion and Implications}

In this study we considered how the FDA and the manufacturer via news releases communicated the uncertainty about the efficacy of the female condom. We also examined newspaper and wire service stories to examine the role of information subsidies in the process of communicating uncertainty about a new medical device. The results suggest a disjuncture in how evidence regarding the female condom's efficacy was construed by the FDA, Wisconsin Pharmacal, and the empirical research. In other words, this case study illuminates the contested nature of the efficacy claims regarding the female condom. The contested nature of the claims can be seen in the range of statistical evidence mentioned by the various parties. The contested nature of the claims also highlighted grey areas in science communication of the female condom- the dearth of comparative studies and the gap between statistical and clinical significance.

The examination of the news releases and news articles suggest that a majority of the articles had efficacy claims about unplanned pregnancy and STI/HIV prevention; however, a range of statistical evidence was mentioned in the news articles and the numerical information was not always consistent with empirical data. Often the stories included some numerical information but left out important contextual information such as mentioning the length of the study, the difference in pregnancy rate of US participants and Latin American participants as well as the lowered pregnancy rates with consistent and correct use. Many of the stories mentioned that the FDA had reservations about the high pregnancy rate, limited clinical data, and lack of evidence regarding the effectiveness and safety of the device. It seems logical for news stories to have included the FDA's reservations given that it is a federal regulatory agency, however, the lack of contextual information may have heightened risk perceptions among the media audience. Recent evidence suggests that among even among highly educated and numerate populations, the presentation of uncertainty in quantitative information in clinical settings reduces understanding and credibility and increases perceptions of risk (Longman, Turner, King, \& McCaffery, 2012).

The FDA is responsible for the regulation of any new medical device and disseminating accurate information regarding its efficacy; clinical research conducted on an investigational device before marketing creates the foundation for claims that will appear on its label once marketing the device receives authorization (Becker, 2006). Many news articles referenced that the packaging information for Reality would include the $26 \%$ failure rate for six months. However, the information itself may have been problematic given the six month expedited approval mentioned in Publication 91-4244 and the exclusion of the fact that with correct use, the failure rate reduced from $12.4 \%$ to $2.6 \%$ in the U.S. These two pieces of information were missing from most of the wire service and articles; instead the failure rate of $26 \%$ was mentioned repeatedly. Mary Ann Leeper, the then Senior Vice-President of Development at Wisconsin Pharmacal disagreed with how the FDA had extended the six-month failure rates to 12-month rates (Wisconsin Pharmacal, May 10, 1993). All but one news wire story (Associated Press, December 13, 1993) and a newspaper story (The Washington Post, December 28,1992$)$ mentioned the Trussell et al. study, which estimated that $21 \%$ of women would become pregnant during the course of the year with typical use and not 26 percent as the FDA claimed. With every perfect use, the female condom had a failure rate of 5\%, compared to $3 \%$ for the male condom. Perhaps the reason why many of the wire and newspaper stories didn't include the pregnancy rate when used correctly is because they used the FDA news release, which did not mention the lower pregnancy rate when used correctly. Nelkin (1995) has suggested, "The complexity and uncertainties of scientific subjects matter reinforce the tendency of journalists to rely on press releases, press conferences, and other prepackaged sources of information" (p. 119). This reliance on news releases often includes "adopting their language as well as their content" (p. 121).

This study also highlights the problem of communicating uncertainty in science communication due to the dearth of comparative effectiveness research and perhaps reporter's lack of understanding of the difference between statistical and clinical significance. All three studies that we found did not include comparative clinical trials. Trussell et al. (1994) touched upon the lack of comparative research in their article suggesting that the efficacy of the female condom could not be compared to other contraceptives and that the 6-month rate was more appropriate than the 12-month rate. The authors suggested that it would be useful to compare the six-month probability of failure for the female condom with other methods especially barrier methods because discontinuation rates for barrier methods are very high such that six-month probabilities are more relevant to the population of potential users ("6-Month vs. 12-Month Rates," para. 
$1-4)$.

By the end of 1993 one Associated Press story said that the "lack of demand" for the female condom was due to the FDA's "conclusion that the female condom has a 26 percent failure rate." The director of the FDA division that regulates birth control devices was quoted as saying that lack of "solid data" had made the FDA doubt the efficacy of the device - the Trussell study had drawn inferences about the female condom's efficacy as compared to other barrier devices and the female condom was approved on the basis of a six-month study, "rather than the customary one-year study". Although the director recognized the female condom's value in AIDS prevention, the agency was concerned that teen-agers might misuse it in trying to prevent pregnancy. Trussell was cited in this story as disagreeing with the FDA; however, he did not consider the dispute over the effectiveness figures to be of paramount importance. He was quoted as saying that the "overwhelming determinant of the effectiveness is whether or not the product is used consistently at every act of intercourse. There wouldn't be a need for the female condom if males used condoms at every act of intercourse" (Associated Press, December 13, 1993). Perhaps his words referenced the difficulty of communicating uncertainty around statistical significance of clinical evidence to decision makers and patients (Han, 2012). His words then were an attempt to put the focus on the clinical significance of the female condom. If used consistently and correctly, the female condom had potential to be a successful barrier method for those couples not inclined to use other barrier methods. Interventions conducted subsequently among different samples have shown that the female condom is effective in preventing STIs (e.g., French et al., 2003) and unplanned pregnancies (e.g., Galvao et al., 2005).

The disjuncture between FDA requirements, Kessler's quotation, and the empirical evidence regarding the effectiveness of the female condom is noteworthy. Becker (2006, p. 5) in delineating the differences in the FDA clinical trial requirements between drugs and medical devices mentions that the approval requirements for drugs require replication of clinical findings whereas for devices a single pivotal clinical trial is sufficient for approval because, "for medical devices, where the mechanism of action is a result of product design and substantially verified by in vitro performance testing, the agency has routinely relied on single studies evaluated for internal and across-center consistency." The evidence seems to suggest that the Dorflinger et al. (1994) study followed FDA guidelines as mandated in Publication 91-4244, however, the mentioning of the failure rates and the attribution of the lack of clinical data by FDA regarding the effectiveness of the female condom even before it was market available is one aspect of the disjuncture.

In conclusion, this study suggests that the FDA's efficacy claims as compared to the manufacturer's claims dominated newspaper and wire service stories during the time female condom received market approval. A majority of the news articles did not present a balanced or an accurate picture of the female condom's efficacy. This could be due to the contested nature of the efficacy claims as evidenced by how they were represented in the news media. Finally, the study also highlights the challenges of communicating uncertainty about a medical device when scientists themselves seem to disagree on the manageability of the uncertainty.

\section{Acknowledgements}

I am grateful to Camille Broadway for her insights on an earlier version of this paper.

\section{References}

Artz, L., Macaluso, M., Brill, I., Kelaghan, J., Austin, H., Fleenor, M., ... Hook III, E. W. (2000). Effectiveness of an intervention promoting the female condom to patients at sexually transmitted disease clinics. American Journal of Public Health, 90(2), 237 - 244. Retrieved from http://ajph.aphapublications.org/

Becker, K. M. (2006). Fundamentals of clinical design and evaluation. In K. M. Becker and J. J. Whyte (Eds.), Clinical Evaluation of Medical Devices (2nd ed., pp. 3 - 21). Retrieved from eBook Collection (EBSCOhost)

Business Wire (December 10, 1992). FDA advisory panel recommends approval of REALITY, the first female condom. [Press release]. Accessed from the LexisNexis ${ }^{\circledR}$ Academic database.

Caldiero, C. T., Taylor, M., \& Ungureanu, L. (2009). Image repair tactics and information subsidies during fraud crises. Journal of Public Relations Research, 21(2), 218 - 228. http://dx.doi.org/10.1080/10627260802557589

Chatterjee, K., \& Markham Shaw, C. (2012). Media portrayals of the female condom. Journal of Health Communication, 17, 1138-1150. http://dx.doi.org/10.1080/10810730.2012.665423

Dorflinger, L., Farr, G., Gabelnick, H., \& Sturgen, K. (1994). Contraceptive efficacy and acceptability of the female condom. The American Journal of Public Health, 84(12), 1960-1964. http://dx.doi.org/10.2105/AJPH.84.12.1960

Editor \& Publisher International Year Book® (1994): The encyclopedia of the newspaper industry. NY: The Editor \& Publisher Co.

Dunwoody, S. (1999). Scientists, journalists, and the meaning of uncertainty. In S. M. Friedman, S. Dunwoody, \& C. L. Rogers (Eds.), Communicating uncertainty: Media coverage of new and controversial science (pp. 59 - 79). New 
Jersey: Lawrence Erlbaum.

FC2 Female Condom® (2012). Available: http://www.fc2femalecondom.com/publicsectorbuying.html

Female Health Company (2012). Available: http://www.femalehealth.com/home.html

French, P. P., Latka, M., Gollub, E. L., Rogers, C., Hoover, D. R., \& Stein, Z. A. (2003). Use-effectiveness of the female versus male condom in preventing sexually transmitted disease in women. Sexually Transmitted Diseases, 30, 433-439. http://dx.doi.org/10.1097/00007435-200305000-00010

Galvao, L. W., Oliveira, L.C., Diaz, H., Kim, D.-j., Marchi, N., Dam, J. v., . . Macaluso, M. (2005). Effectiveness of female and male condoms in preventing exposure to semen during vaginal intercourse: a randomized trial. Contraception, 71, 130-136. http://dx.doi.org/10.1016/j.contraception.2004.08.008

Gandy, Jr., O.H. (1982). Beyond agenda setting: Information subsidies and public policy. Norwood, NJ: Alex Publishing Company.

Han, P. K. J. (2012). Conceptual, methodological, and ethical problems in communicating uncertainty in clinical evidence. Medical Care Research and Review. Supplement to 70(1), 14S-36S. http://dx.doi.org/10.1177/1077558712459361.

Heavey, S. (2009, March 11). New, cheaper female condom wins U.S. approval. Retrieved from http://www.reuters.com/article/2009/03/11/us-femalehealth-condom-idUSTRE52A2V020090311

Kaler, A. (2004a). The female condom in North America: Selling the technology of 'empowerment.' Journal of Gender Studies, 13, 139 - 152. http://dx.doi.org/10.1080/0958923042000217819

Kaler, A. (2004b). The future of female-controlled barrier methods for HIV prevention: female condoms and lessons learned. Culture, Health \& Sexuality, 6, 501-516. http://dx.doi.org/10.1080/13691050410001701948

Keagy, B., \& Levin, D. (2012). Medical device trials: Understanding the United State's regulatory pathway and clinical operations. Applied Clinical Trials, 21, 36-41.

Kiousis, S., Kim, S-Y., McDevitt, M., \& Ostrowski. (2009). Competing for attention: Information subsidy influence in agenda building during election campaigns. J\&MC Quarterly, 86(3), 545-562. http://dx.doi.org/10.1177/107769900908600306

Leary, W. E. (1993, May 11). Female condom approved for market. The New York Times, p. C5.

Leeper, M. A., \& Conrardy, M. (1989). Preliminary evaluation of REALITY, a condom for women to wear. Advances in Contraception, 5, 229-235. http://dx.doi.org/10.1007/BF01890894

Lindlof, T. R., \& Taylor, B. C. (2002). Qualitative Communication Research Methods (2nd ed.). Thousand Oaks: Sage.

Longman, T., Turner, R., King, M., \& McCaffery, K. J. (2012). The effects of communicating uncertainty in quantitative health risk estimates. Patient Education and Counseling, 89, 252-259. Http://dx.doi.org/10.1016/j.pec.2012.07.2010

Luce, B. R., \& Brown, R. E. (1994). The impact of technology assessment on decisions by health care providers and payers. In A. C. Gelijns and H. V. Dawkins (Eds.), Adopting new medical technology (pp. 49 - 60). Washington, D.C.: National Academy Press.

McCarthy, M., Brennan, M., De Boer, M., \& Ritson, C. (2008). Media risk communication - what was said by whom and how was it interpreted. Journal of Risk Research, 11(3), 375-394. http://dx.doi.org/10.1080/13669870701566599

Nelkin, D. (1995). Selling Science (Revised Edition): How the press covers science and technology. New York: W. H. Freeman and Company.

Parrott, R. L., \& Condit, C. M. (1996). Evaluating Women's Health Messages. Thousand Oaks, CA: Sage Publications, Inc. http://dx.doi.org/10.4135/9781483345437

PR Newswire (August 3, 1992). Wisconsin Pharmacal Company announces submission of data to the FDA on female condom [Press release]. Accessed from the LexisNexis ${ }^{\circledR}$ Academic database.

Rivera, R. (1991). Condoms and female barrier contraceptives. In The regulation of AIDS-related medical devices. HHS Publication FDA 91-4244 (pp. 27 - 30). Center for Devices and Radiological Health, Rockville, MD.

Soper, D. E., Shoupe, D., Shangold, G. A., Shangold, M. M., Guttman, J., \& Mercer, L. (1993). Prevention of vaginal trichomoniasis by compliant use of the female condom. Sex Transm Dis. 20, 137-9. PubMed PMID: 8511706. http://dx.doi.org/10.1097/00007435-199305000-00003 
Trussell, J., Sturgen, K., Strickler, J., Dominik, R. (1994). Comparative contraceptive efficacy of the female condom and other barrier methods. Family Planning Perspectives, 26, 66 - 72. http://dx.doi.org/10.2307/2136004

United State Food and Drug Administration. (1993). Statement by the Food and Drug Administration [Press Release]. Retrieved from http://www.fda.gov/Forconsumers/

U. S. Food \& Drug Administration. (2009). Device approval and Clearances: FC2 Female Condom-P080002. Retrieved from

http://www.fda.gov/MedicalDevices/ProductsandMedicalProcedures/DeviceApprovalsandClearances/Recently-Ap provedDevices/ucm133900.htm

Woloshin, S., \& Schwartz, L., M. (2002). Press releases: Translating research into news. The Journal of the American Medical Association, 287, 2856-2858. http://dx.doi.org/10.1001/jama.287.21.2856.

\section{Footnotes}

[1]. The newspaper sample from 1993 has been used in a previously published study.

\section{(cc) EY}

This work is licensed under a Creative Commons Attribution 3.0 License. 